\title{
Gastroenterology in Romania: a fresh start in a new era
}

This month's 'International Gastroenterology' section features an article on the difficulties associated with establishing a gastroenterology journal in Romania following the overthrow of the totalitarian regime in 1989. Clearly there are shared problems common to editors of all new journals: getting papers and readers, for a start. The liberal scientific tradition in the West, however, has always encouraged discussion, debate, and disagreement while the editorial process depends on vigorous (but constructive) peer review. This is not so in Romania where criticism has been regarded as hostile, personal, and potentially dangerous.

Gut sends its best wishes to the Romanian fournal of Gastroenterology.

Enthusiasm emanating from a group of Romanian professionals who had been controlled and silenced for several decades was the constructive force in the origin of the Romanian fournal of Gastroenterology. Dissatisfaction with the state of imposed apathy surrounding them generated a desire for change: to show that we exist and have something worthwhile to say in the medical field.

In the free publishing history of Romania, which really only began in 1989, many medical journals have appeared - some have survived but many others have failed. The Romanian fournal of Gastroenterology is one of the survivors. The preliminary planning for its foundation began in 1990 but the first issue did not appear until February 1992. Since then it has been published quarterly respecting one of the basic obligations a journal owes to its subscribers regularity. It is now in its third volume and also has included two supplements - abstracts of the National Congresses. As a consequence of its publishing programme the number of subscribers has grown steadily. At the beginning it was the official journal of the Romanian Society of Gastroenterology and Digestive Endoscopy but it soon also became the official journal of the local association for the Study of the Liver and also the Society of Hepato-Bilio-Pancreatic Surgery. These four societies are not large but together they cover the specialty of gastroenterology and the connected specialties in this country.

As we wished for a wider audience for our journal from the international research community, we decided to publish all articles in English. Some were also accepted in French, the language traditionally spoken by Romanians given the common Latin origin of both peoples but these had an English summary as well. Native English speakers were asked to proof read the journal to ensure that the terms used were precise and the messages clear and distinct creating few problems for readers lacking English fluency. A Romanian abstract was also published. A Romanian translation was also given for debates on specific problems - like training and education - which were expected to generate the interest of specialists and be followed by debate and for the literature review chapters.

The main responsibilities assumed by the Romanian Fournal of Gastroenterology are:

(1) To update Romanian gastroenterologists and improve their professional training, medical communication and education, and, in addition, to stimulate research and rebuild academic gastroenterology. Therefore, it publishes reviews, editorials, and original papers written by Western specialists with the aim to reach uniform standards of training and practice in gastroenterology.
(2) To publish selected original papers from Romanian gastroenterologists to publicise their interests and performances to the Western world.

(3) To strengthen links from the former Eastern European bloc by distributing the journal and publishing articles from these countries.

Have these goals been fulfilled in its first three years of publication? More than $90 \%$ of the original articles and case reports came from Romania while about $75 \%$ of the editorials and reviews were written by Western personalities. In this way we tried to ensure the 'internationality' of the journal at least in one sense: through the nationality of published items. At the same time we had to keep a balance between Romanian (67\%) and Western contributors (33\%), being well aware that a journal with many Western contributions will receive more local credibility but on the other hand may also undermine international confidence in ourselves. Contributions from Eastern European countries have been very few - only three original papers - but we have succeeded in gaining some subscribers in Hungary, Republic of Moldova, and Yugoslavia.

The specific conditions in our country gave rise to many problems in producing the journal:

\section{(1) Financing the journal}

The launching and expansion of the journal have occurred large costs, measured both in effort and money. Financing was obtained from varied, though limited, sources:

(a) Subscriptions - the subscription fee is set low to make the journal easily accepted and to raised the number of subscribers with the result that the net gain from the subscriptions is only a small contribution to the costs of the journal. The escalating prices of paper and printing are changing the cost for every issue: the costs for the September 1994 issue, for example, were equivalent to the 1994 annual subscription fee.

(b) Advertisements - a major problem in attracting advertisers is still the comparatively limited circulation of the journal in Romania. Drug companies prefer to advertise at lower prices in general information newspapers, which have a larger audience.

(c) Sponsorship - the sponsorship law was only promulgated in 1994 and has been slow in getting off the ground. Only a very small percentage of local company revenue can be offered as sponsorship because of the low economic level of our country and naturally there is much competition for it.

(d) Donations - similar to sponsorship, donations were obtained through the personal efforts of the local editors. 
The first donor of the journal was SOROS Foundation for an Open Society, Romanian Branch. It financed the first two issues of the journal and recently provided an excellent computer. Other donations came from charitable associations.

It is obvious that in the field of journal financing, we still have to identify some extra resources in the future.

\section{(2) Selection of manuscripts for publication}

When the journal was launched, we hoped to receive more manuscripts from Romanian authors incorporating a higher standard. Not everyone believed this goal could be achieved as sceptics thought that there was not enough good scientific material, that writers of good papers would seek more established journals, and that the audience for an English written journal would be limited. In fact, the number of submitted manuscripts as well as their quality have gradually increased. Authors were asked for a written assurance that the manuscript had not and would not appear elsewhere to prevent duplicate publication. Such an assurance is still not a common request for medical journals in Romania.

Although we also consider manuscripts that have been rejected by international journals we subject them to the peer review process. The peer review of the manuscript was made by a local and an international reviewer. An important problem here was that some of the international reviewers did not reply and others replied too late - only a few responded regularly. On the other hand local reviewers were quick to answer but in some cases were even more critical than the international reviewers. Another problem was the low rate of acceptance of our contributions by the Western reviewers though in some cases they recommended publication even if the information was not exactly current because it might be of interest to our readers.

Because of the relatively reduced number of manuscripts submitted and the need to respect the punctuality of publication, the early acceptance rate for publication was quite high -80 per cent. Our editorial restraint has paid off though and this year this rate has decreased as we have a larger pool of papers for selection.

The published manuscripts should become subject to debate although this again is not common practice in Romania. The old mentality still persists where criticism was taken as a personal insult - freedom of speech was never permitted. A correspondence corner will soon be introduced. Positive criticism will serve the goal of educating both the authors and the readers.

\section{(3) Popularising the journal}

Firstly, we advertised in Romania by placing notices in medical newspapers and even on the local television. Secondly, free copies of the journal were distributed to all the medical libraries in the country. Not many subscribers were gained, however, because of inadequate library budgets and of existing bureaucracy in the acceptance of new titles.

Outside Romania we tried to set up exchanges with the most important libraries in Europe. We succeeded with both the British Library, and the library of the British Medical Association from where we now receive two British journal titles in exchange. In addition we obtained two subscriptions from German libraries and set up exchange agreements with five medical libraries in Yugoslavia.

Naturally the most important achievement of a new journal is to gain entry in the major indexing journals. The Romanian journal has been accepted by the HepatofalkRapid Literature Review in Germany and is awaiting the decision of the Excerpta medica office. The National Library of Medicine has refused, however, to accept the journal in Index Medicus at the first attempt and for the moment the journal will probably not be covered by the ISI Current Contents as it has not yet gained international interest. We have been invited by both institutes to reapply after two years. Until then Romanian gastroenterologists will continue to send their manuscripts in the first place to other journals that are indexed, which is understandable. This may result in a catch 22 situation whereby less original and interesting manuscripts will be published in our journal and because of this we have fewer chances to be accepted by the major indexing journals.

Despite these difficulties, the editorial board realises it has succeeded where many have failed and looks forward with excitement and in anticipation to the next few years in the life of its journal.

MONICA ACALOVSCHI

3rd Medical Clinic, Department of Gastroenterology,

University of Medicine and Pharmacy,

Cluj-Napoca, Romania 